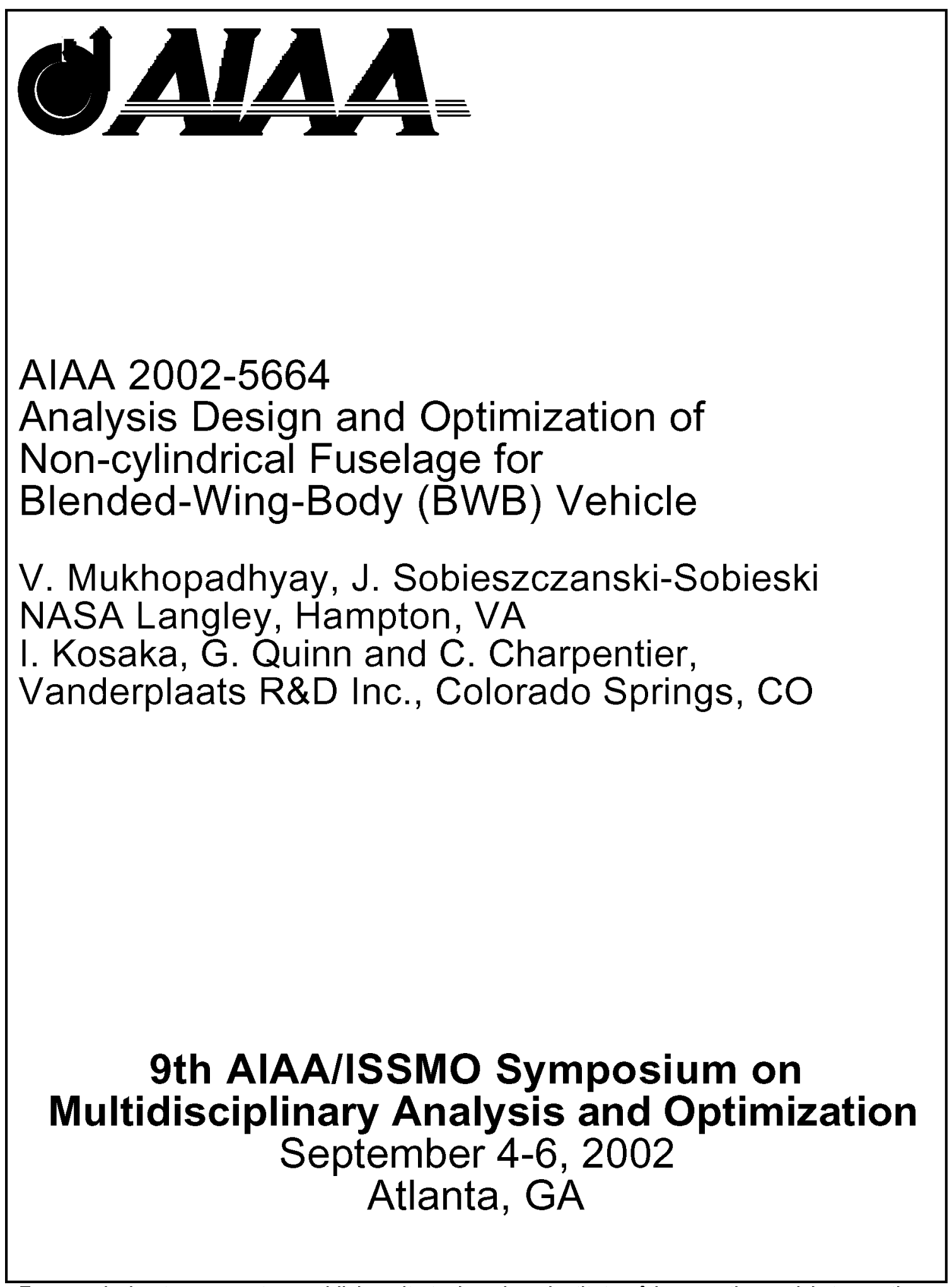

For permission to copy or to republish, write to American Institute of Aeronautics and Astronautics, 1801 Alexander Bell Drive, Suite 500, Reston VA 20191-4344 


\title{
ANALYSIS, DESIGN AND OPTIMIZATION OF NON-CYLINA FUSELAGE FOR BLENDED-WING-BODY (BWB) VEHICLE
}

\author{
V. Mukhopadhyay*, J. Sobieszczanski-Sobieski** \\ NASA Langley Research Center, Hampton, VA \\ I. Kosaka, G. Quinn and C. Charpentier, \\ Vanderplaats R\&D Inc. Colorado Springs, CO
}

\begin{abstract}
$\underline{\text { Abstract }}$
Initial results of an investigation towards finding an efficient non-cylindrical fuselage configuration for a conceptual blended-wing-body flight vehicle were presented. A simplified 2-D beam column analysis and optimization was performed first. Then a set of detailed finite element models of deep sandwich panel and ribbed shell construction concepts were analyzed and optimized. Generally these concepts with flat surfaces were found to be structurally inefficient to withstand internal pressure and resultant compressive loads simultaneously. Alternatively, a set of multi-bubble fuselage configuration concepts were developed for balancing internal cabin pressure load efficiently, through membrane stress in inner-stiffened shell and intercabin walls. An outer-ribbed shell was designed to prevent buckling due to external resultant compressive loads. Initial results from finite element analysis appear to be promising. These concepts should be developed further to exploit their inherent structurally efficiency.
\end{abstract}

\section{Introduction}

In revolutionary Blended-Wing-Body (BWB) megatransport concepts ${ }^{1,2}$ with non-cylindrical liftingbody fuselage and in conformal shaped propellant tanks of reusable launch vehicles ${ }^{3}$, the pressurized structure must be designed to resist internal pressure and compression due to overall bending. These loads combine in a nonlinear manner to induce severe deformation, and high stresses, that might necessitate significant structural weight penalty. In addition, resulting deformation of aerodynamic surface could significantly affect performance advantages provided by lifting body. This problem was investigated for Airbus type elliptic-section composite fuselage as well as for BWB and X33 with special sandwich composite skin and metal honeycomb core. ${ }^{1,3,5}$ In previous BWB studies, ${ }^{6,7}$ effects of cabin shape, and volume were investigated, from a baseline configuration using an aerodynamic based optimization scheme, but structural design with internal pressure or

- Associate Fellow, **Fellow, AIAA buckling issues were not addressed. In another conceptual structural analysis ${ }^{5}$, several promising non-cylindrical fuselage configurations were identified but no optimization study was conducted.

This paper presents additional sizing, analysis, design and optimization results towards finding an efficient non-cylindrical BWB configuration, considering both internal pressure and compressive load including buckling stability. Initially four idealized deep sandwich and ribbed shell configurations were analyzed and optimized with stress and buckling constraints. These panels represented a critical upper surface panel section, as shown in Fig. 1.

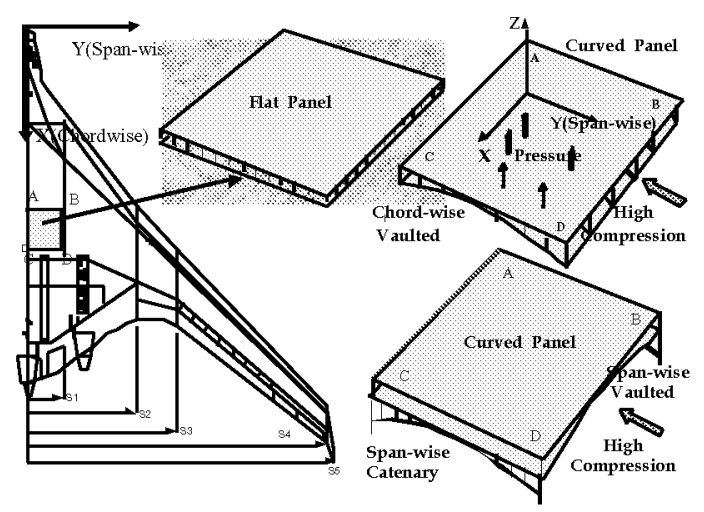

Fig. 1 Conceptual configurations of flat and curved top surface panel

In an alternative approach, several multi-bubble stiffened fuselage section concepts were developed. This special configuration resists internal pressure load through membrane stress balance, while resisting bending and compression load with an outer stiffened ribbed shell. The multi-bubble concept was then refined further, to meet critical design requirements with minimal weight increment.

The knowledge gained in this conceptual design study would provide the designers with options to make BWB revolutionary concept both structurally feasible and aerodynamically efficient. This could also give BWB development a competitive advantage over the Airbus ${ }^{8}$ A380 in the 
lucrative 500-800 passenger long range travel markets.

\section{2-D Beam-Column Analysis}

Some initial sizing, stress and deflections were estimated using analytical nonlinear beam-column solutions $^{9}$ for a 2-D simply-supported beam representing a simplified cabin roof that acts as a surface of a pressure vessel and as a compressed flange of a beam in bending. Maximum deflection $z_{\max }$, bending moment $M_{\max }$ and stress $\boldsymbol{\sigma}_{\max }$ at mid span for simply-supported boundary condition are given by Eqs. (1-3).

$$
\begin{aligned}
& z_{\max }=\frac{5 p r \cdot l^{4}}{384 E I} \frac{12\left(2 \sec \boldsymbol{\mu}-2-\boldsymbol{\mu}^{2}\right)}{5 \boldsymbol{\mu}^{4}} \\
& M_{\max }=\frac{p r \cdot l^{2}}{8}+\frac{5 p r \cdot l^{4}}{384 E I} \frac{12\left(2 \sec \mu-2-\mu^{2}\right)}{5 \mu^{4}} P \\
& \boldsymbol{\sigma}_{\max }=M_{\max } \frac{d}{2 I}+\frac{P}{2 W t}
\end{aligned}
$$

where $P_{c r}=\pi^{2} E I / l^{2}$ and $\mu=\frac{\pi}{2} \sqrt{\frac{P}{P_{c r}}}$

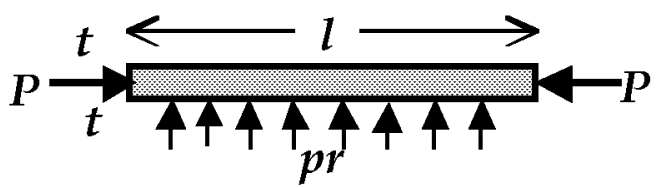

Here $P$ denotes distributed axial compressive load, $p r$ denotes transverse cabin pressure load, $I$ denotes bending moment of inertia, $E$ denotes Young's modulus and $l$ denotes column length as shown in the sketch. Note that stresses and deflections from Eqs.(1-2) diverge as $P$ approaches critical compressive buckling load $P_{C r}$. Let us assume $I=0.5 t w(d-t)^{2}$, where $d$ is beam depth, $t$ is thickness of top and bottom flange or face sheet and $w$ is unit width. Initially let us assume face skin thickness $t=0.006$ meter, beam depth $d=0.15$ meter, beam length $l=3.5$ meter, transverse pressure $p r=84830$ Pascals (12.3 pounds per square inch) and axial compressive load $P=165,000 \mathrm{~kg} /$ meter. The face sheet material of the sandwich was assumed to be aluminum AL7075-T6 with Young's modulus $E=7.1 \times 10^{10} \quad$ Pascals, allowable stresses $F_{t u}=5.24 E+8$ Pascals, $F_{t y}=4.55 E+8$ Pascals and $F_{c y}=4.62 E+8$ Pascals.

The resulting buckling load ratio $P / P C r$ was close to 0.4 . The non-dimensional mid-span deflection ratio $Z_{\max } / d$, maximum compressive stress ratio $\boldsymbol{\sigma}_{\text {max }}$ /Yield stress $F c y$ and maximum bending moment ratio $\operatorname{Mmax} /\left(\mathrm{prl}^{2} / 8\right)$ variation with
$P / P c r$ are shown in Figs. 2a-c. Figs.2a,b indicate that, for $P / P c r=0.4$, mid-span deflection is about $40 \%$ of beam depth, and maximum combined compressive stress $\boldsymbol{\sigma}_{\max }$ is about $80 \%$ of the allowable compressive yield stress Fcy.

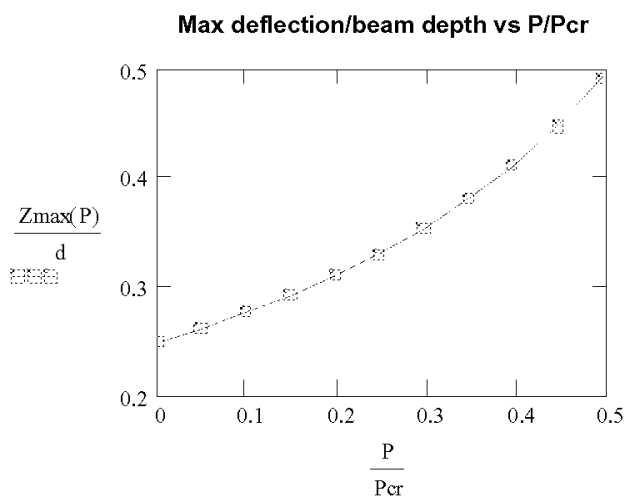

Maximum Stress/Yield Stress vs. P/Pcr

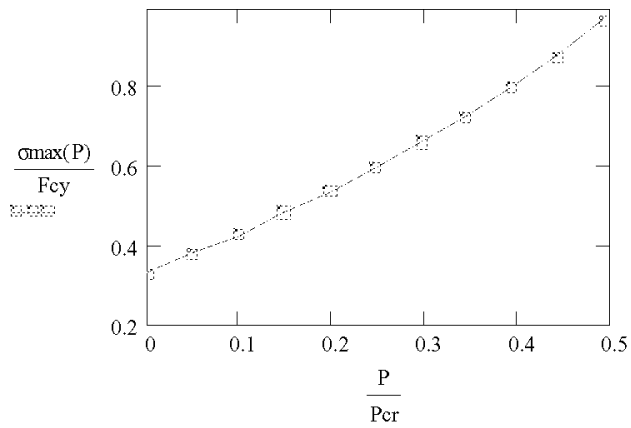

MAXIMUM BENDING MOMEN/(pr./2/8) vs. PIPcr

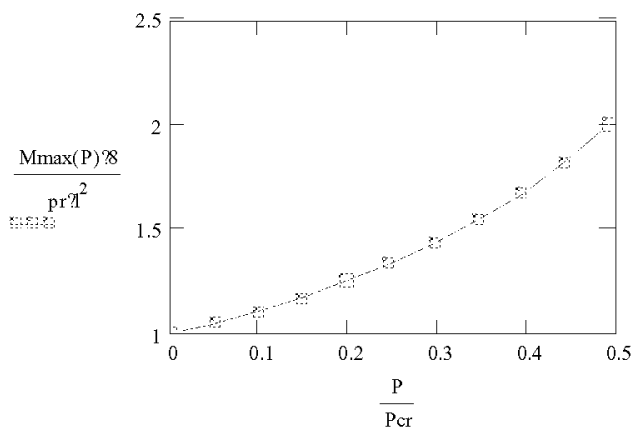

Figs. 2a-c. Mid-span deflection $Z_{\max } /$ beam depth̆, maximum compressive stress ratio $\sigma_{\max } / F_{c y}$ and maximum bending moment ratio $M_{\max } /(p r . l / 8)$ variations with axial compressive load $P / P C r$ for an idealized simply-supported beam-column.

Fig.2c shows that for this beam-column, additional bending moment caused by beam deflection is almost $40 \%$ of that due to transverse pressure load alone. The top and bottom flange or 
skin panel weighs about $36 \mathrm{~kg} / \mathrm{sq}$ meter, and the honeycomb core weighs $6.4 \mathrm{~kg} / \mathrm{sq}$.meter. A quick spreadsheet based weight optimization was performed with beam depth and skin thickness as design variables and $P / P C r<0.66, Z \max / d<1$ and $\boldsymbol{\sigma}_{\text {max }} / F_{c y}<1$ as constraints. Results are presented in Table 1. The unit weight ratio was reduced to 38 $\mathrm{kg} / \mathrm{sq}$ meter by increasing $d$ to 0.026 meter and reducing $t$ to 0.0045 meters.

This simple but conservative non-linear analysis and optimization was used for sizing the three dimensional concepts. This also illustrates the weight penalty and high stress problem associated with resisting normal pressure by bending stress. In this beam of length $l$, bending stress is proportional to $\left(p r . f^{P}\right) /(d . t)$ while in a cylindrical pressure vessel of radius $R$, resulting membrane stress is proportional to $(p r . R / t)$. Assuming $R$ is of same order as $l$, the beam has much higher stress and is consequently much heavier. The problem is aggravated by the non-linear effect of compressive load acting on the deflected beam or plate. So in order to obtain an efficient structure, one must increase the bending stiffness using deep sandwich shell with light weight high-strength composite skin and honeycomb core. This investigation is described next.

\section{Panel FEM Analysis}

Four idealized top fuselage surface composite panel configurations were analyzed and optimized for minimum weight, under internal pressure and estimated compressive loads with both stress and buckling constraints. These finite element analyses and optimization were done using a tool described in $\operatorname{Ref} 10$

Fig. 1 shows possible location of this critical top surface panel on a BWB plan-form. These four panel configurations, namely, a) Flat Honeycomb sandwich panel: b) Flat Double skin cross-ribbed panel c) Flat honeycomb panel with span-wise catenary and d) Span-wise vaulted shell with rod stiffeners are shown in Figs. 3a-3d, respectively. Estimates of design loads at $2.5 \mathrm{~g}$ flight condition were obtained from previous BWB analyse ${ }^{1,2}$. In addition to internal cabin pressure load of 84830 Pascals, these panels were subjected to an estimated resultant span-wise compressive load of $165,000 \mathrm{Kg} /$ meter and a chord-wise tensile load of $12500 \mathrm{Kg} /$ meter. An orthotropic graphiteepoxy composite material was used for the skin and aluminum honeycomb was used for the sandwich core $^{1,2,5}$. Two sets of approximate boundary conditions were used, as shown in Figs. $3 \mathrm{a}$ and $3 \mathrm{~d}$ respectively. Rigid elements were used at some edges for compatibility. Edge elements at boundary were excluded for stress constraint evaluation to prevent local stresses from applied boundary conditions from driving the design.

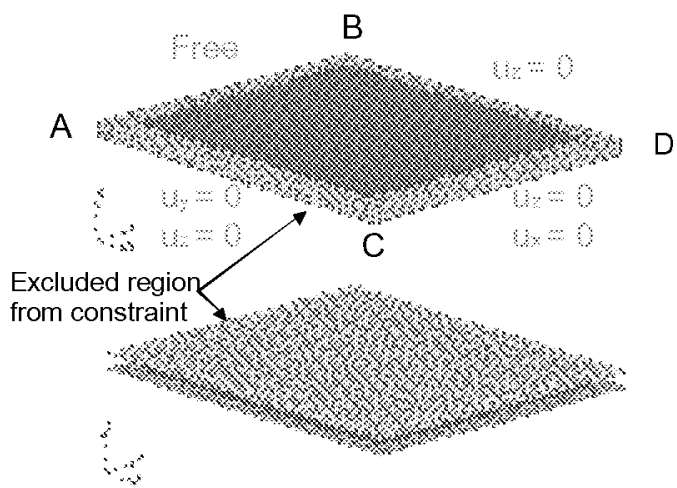

3a. Flat Honeycomb sandwich panel showing first set of boundary conditions:

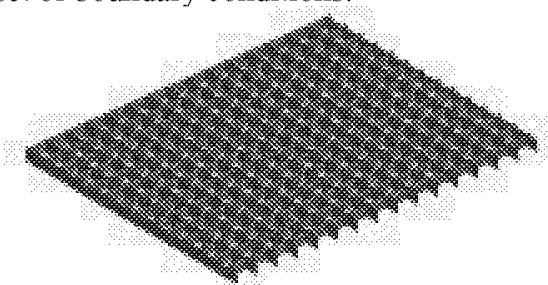

3b. Flat Double-skin cross ribbed panel

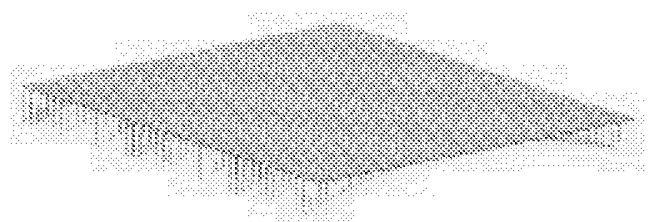

3c. Flat honeycomb panel with span-wise catenary

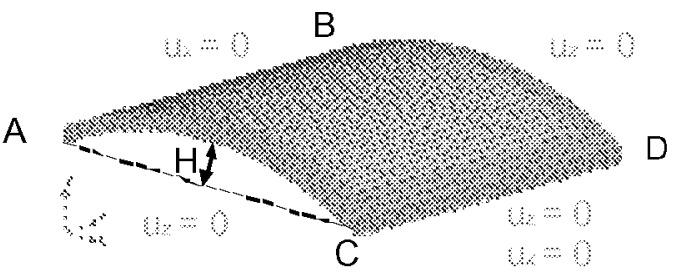

3d. Span-wise vaulted shell with bar stiffener, showing second set of boundary conditions.

Figs. 3a-3d. Four idealized panel configurations.

Flat Honeycomb sandwich panel:

A baseline graphite-epoxy composite sandwich $3.5 \times 3.8$ meter rectangular panel with 0.003 meter thick top and bottom skin and a honeycomb core was first considered. The panel depth and skin thickness were treated as design variables. The baseline panel weight was about $15.3 \mathrm{~kg} / \mathrm{sq}$. meter. The constrained optimized weight with first set of boundary conditions increased to $28.5 \mathrm{~kg} / \mathrm{sq}$. meter. With second set of boundary conditions, optimized 
weight was close to $24.5 \mathrm{~kg} / \mathrm{sq}$. meter. A summary of result is presented in Table 1 .

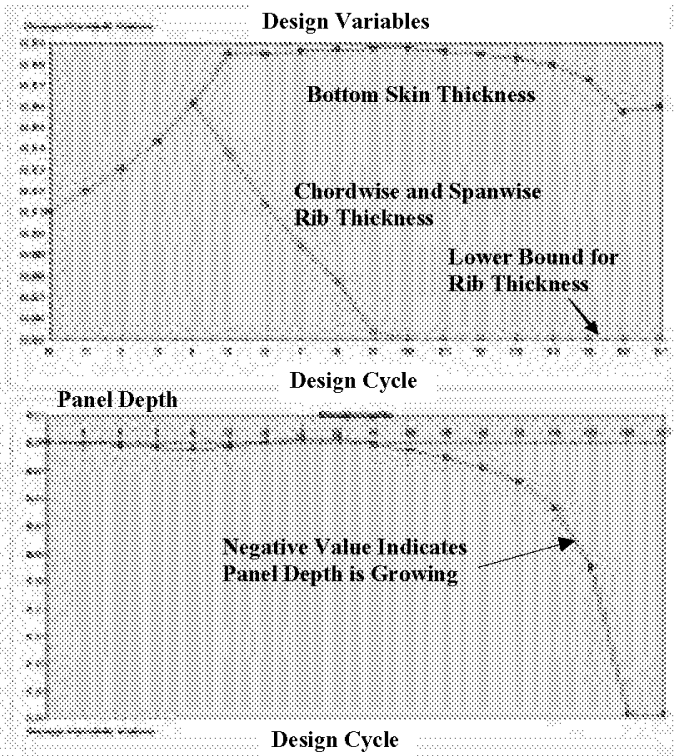

Fig. 4 Design variable history from initial results of a flat double-skin ribbed panel optimization with only stress constraints and pressure load.

\section{Flat Double-skin ribbed panel:}

A baseline double-skin cross-ribbed panel of same dimension was also analyzed, as an alternative to thick honeycomb panel. The panel depth, web and skin thickness were treated as design variables. The baseline graphite epoxy ribbed panel weight was about $13.5 \mathrm{~kg} / \mathrm{sq}$. meter with 14 chord-wise ribs and 16 span-wise ribs at 0.25 meters interval. Based on simple plate buckling analysis ${ }^{12-14}$, span-wise and chord-wise cross-rib spacing was determined to prevent local panel buckling. Fig. 4 shows initial results of this double-skin ribbed panel optimization with only internal pressure load and stress constraints. The optimizer tended to increase the lower skin thickness and panel depth, while reducing the span-wise and chord-wise rib thickness. This resulted in marginal reduction of weight by about $18 \%$.

However, with both stress and buckling constraints, under the estimated compressive load, the skin thickness increased significantly after optimization. Consequently, the weight (objective function) of the optimized panel with first set of boundary condition actually increases by over $240 \%$ as shown in Fig. 5. With second set of boundary condition, and edge elements excluded, the results were somewhat reasonable. Optimized panel weight was $25.6 \mathrm{~kg} / \mathrm{sq}$ meters. The fine mesh FEM model exhibited many lower local plate buckling modes, due to the manner in which the compressive loads were applied at nodes, to represent the bending loads approximately. Hence, a course mesh was used to capture overall panel buckling modes for optimization purposes.
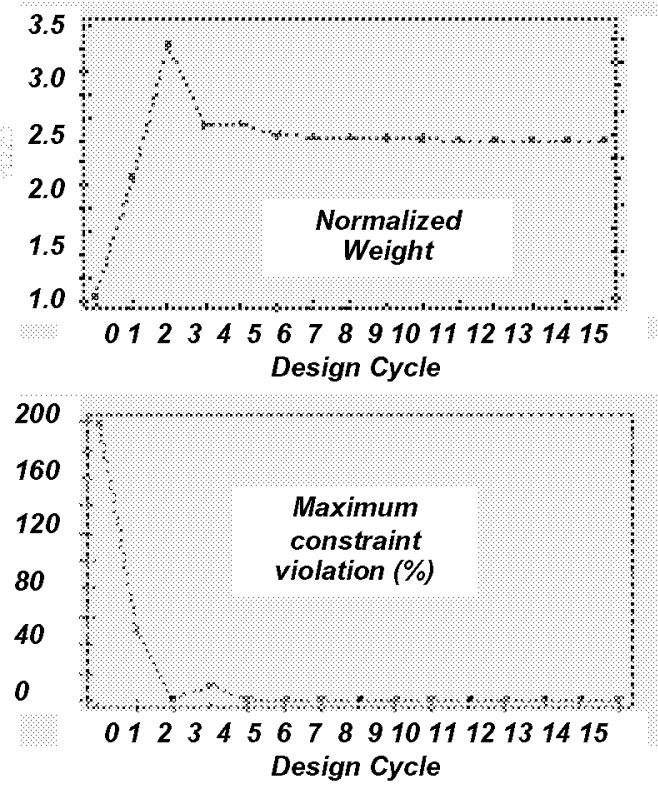

Fig. 5 Objective function and constraint violation history from initial results of a double-skin ribbed panel optimization under both stress and buckling constraints with combined compressive and pressure loads.

Flat Honeycomb panel with catenary cable:

A catenary cable support system with vertical rod connections to the honeycomb panel was used to reduce deflection, much like a suspension bridge, as shown in Fig. 3c. However, optimization results were similar to the previous cases. Catenary cables were marginally beneficial for reducing lower skin thickness assuming that the deflections and loads keep the cable system in tension.

Span-wise vaulted shell with rod stiffener:

This concept used a span-wise vaulted shell to contain pressure efficiently. Three span-wise bar elements were added for increasing buckling stiffness, as shown in Fig. 3d. Spanwise vaulting also increases stiffness to compressive load, thus it required less skin thickness but exhibited higher deflections.

The optimization results and weight estimates shown in Table 1 were not surprising and were consistent with the 2-D non-linear beamcolumn analysis from Eq.(1-3) and with earlier design results presented in Ref. 5. Thus it became apparent that inner cylindrical segments of fuselage were necessary in order to contain pressure efficiently through membrane stress. The membrane in-plane forces at the fuselage junction 
could be symmetrically balanced in tension using the inter-cabin wall, thus avoiding major bending stresses at the junction. Thus, the outer superstructure at the top and bottom part of the fuselage could be used to resist the span-wise bending load, yet retain aerodynamic shape and smoothness. This led to the design of a set of multi-bubble structural concept, as described next.

\section{Conventional Fuselage}

A number of stiffened aluminum fuselage configurations shown in Figs. 6-9 were initially analyzed, for acceptable stress and deflection with 127530 pascals (18.6 psi) internal pressure loads only. These finite element models were developed in-house and analyzed using a tool described in Ref. 11. An idealized Airbus A380 elliptic-section fuselage and a baseline cylindrical section fuselage with hoop stiffeners, shown in Figs 6-7, were first analyzed for comparison purposes.

Elliptic section fuselage:

A 10 meters long section with 3 floors, as shown in Fig. 6, was analyzed first, in order to compare cylindrical versus elliptic section fuselage strength characteristics under internal pressure. The 8.5 meters high, $7 m$ wide Airbus A380 type stiffened elliptic section, shown in Fig. 6, was stiffened with 21 ring stiffeners, each $0.1 \mathrm{~m}$ eter deep at 0.5 meter interval. Thickness of skin and ring stiffeners were assumed to be 0.003 meters. These values are generally typical for commercial transport aircraft ${ }^{12,14}$. Maximum displacement from the FEM analysis was about 0.153 meters at top and bottom of the fuselage. The resulting nodal Von-Mises stresses at the shell element top surface are shown in Fig. 6. Average Von-mises stress on the skin was of the order $3.5 E+8$ pascals which is 2.1 times the ideal hoop stress $p r . D / 2 t$. No buckling analysis was done. FEM weight of this section was $3828 \mathrm{~kg}$ with total floor area of $177 \mathrm{sq}$. meters.

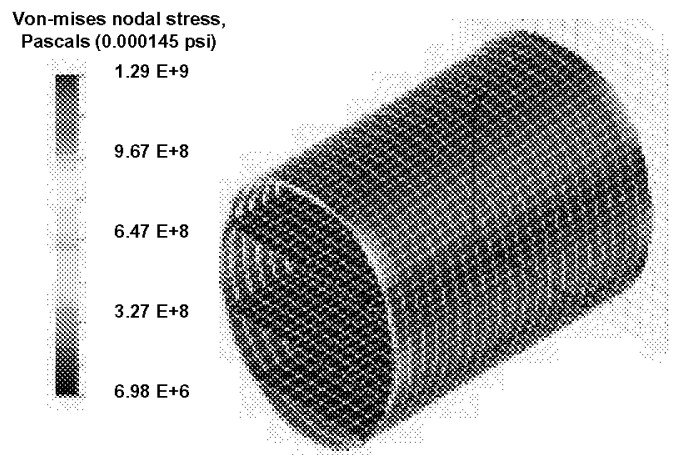

Fig. 6 A380 type $8.5 m \times 7 m$ stiffened elliptic section fuselage: Element Von-Mises stresses due to 127530 Pascals (18.6 psi) internal pressure.

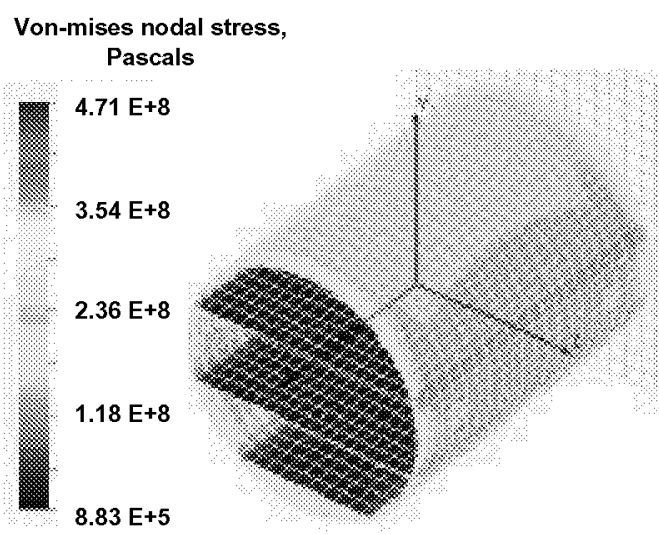

Fig. 7 Baseline stiffened cylindrical fuselage: 7.75 meter s diameter: Nodal Von-Mises stress due to 127530 pascals (18.6 psi) internal pressure.

Baseline cylindrical section fuselage:

The cylindrical section with 7.75 meters diameter, shown in Fig. 7, had same circumference as the elliptic section. It was also stiffened with ring stiffeners, each 0.1 meter deep, at 0.5 meters interval. Thickness of skin and ring stiffeners was assumed to be 0.003 meters. This cylindrical section fuselage was also subjected to 127530 Pascals internal pressure. Maximum displacements were of the order 0.035 meters. The resulting nodal Von-Mises stresses at the shell element top surface are shown in Fig. 7. Average Von-Mises stress on the skin was of the order $2.6 E+8$ Pascals which is about 1.5 times the ideal hoop stress given by pr.D/2t. No buckling analysis was done. FEM weight of this section was $3943 \mathrm{~kg}$ with total floor area of 192 sq. meters. For this cylindrical section, FEM stresses were significantly lower, and had higher floor area, although net weight was slightly higher.

\section{Multi-bubble Fuselage}

Based on the lessons learned from these analyses, 3floor load-balanced multi-bubble stiffened-shell pressure vessel concepts were developed. Diameters of the cylindrical segments were almost same as the cylindrical segment previously described. In this design the two merging bubble-sections meet with the inter-cabin vertical wall at an angle, so that surface in-plane membrane forces are in selfequilibrium $^{12}$. Thus in an ideal case, the resulting membrane stresses on the cylindrical section skin are balanced by tension in the inter-cabin walls. This geometrical arrangement could reduce undue bending at these joints, thereby preserving the advantage of a cylindrical section fuselage, under internal cabin pressure. This special geometry results in 3-floor multi-aisle fuselage, each 5.8 meters wide. In this and subsequent FEM models, 
cylindrical skin segments were stiffened with $10 \mathrm{~cm}$ deep ring stiffeners, that were modeled by beam $3 \mathrm{~d}$ elements. These $I$ beam stiffeners, with $5 \mathrm{~cm}$ wide flange, $10 \mathrm{~cm}$ deep web and $3 \mathrm{~mm}$ thick flange and web, were used at 0.5 meter chord-wise interval on all cylindrical surfaces, inter-cabin walls and floors. These values are generally typical for commercial transport aircrafts ${ }^{12,14}$.

\section{Four-bubble Fuselage:}

This force-balanced bubble concept was examined for double and triple bubble configurations and then extended to a four-bubble 3-floor concept with additional outer stiffened double panels, at top and bottom of the fuselage. These outer panels initially consisted of two stiffened shells $25 \mathrm{~cm}$ apart and were supported by the cylindrical inner fuselage sections at midpoint. These outer shells were not connected to the inter-cabin vertical walls directly, as shown in Fig. 8, at top. The outer shell was added to provide bending and buckling stiffness to span-wise bending loads that were not considered in the double- and triple-bubble concepts. This model was subjected to the standard 84835 pascals internal cabin pressure as load case 1 . For load case 2, top stiffened panels were subjected to $164350 \mathrm{~kg} /$ meter span-wise compressive loads. Equal and opposite tensile loads were applied at bottom panels, to represent an equivalent maximum estimated bending moment.

Figure 8 shows element nodal Von-Mises stress at top due to 84835 Pascals internal cabin pressure and $164350 \mathrm{~kg} /$ meter span-wise compressive load on top panel and equal tensile load at bottom panel. Maximum displacement was of the order 0.05 meter. Skin thickness was assumed to be 0.003 meters except for that of outer double wall which was 0.005 meters. Total weight of this section ( $8.25 \mathrm{~m}$ high, $19.325 \mathrm{~m}$ wide, $5 \mathrm{~m}$ long) was about $11000 \mathrm{~kg}$. Buckling safety factor was not satisfied for assumed boundary condition. To increase buckling stiffness, cross ribs were later added (Fig. 8 ) to the outer double walls at 0.25 meters chordwise interval and 0.18 meters spanwise interval. FEM weight was $13100 \mathrm{~kg}$ with cross ribs. Total floor area was $267 \mathrm{sq}$. meters. Buckling safety factor was about 1.0 for the compressive load. However undesirable lower local bucking modes of the cargo floor panel for reversed loading were present. Overall, this design was better but not satisfactory.

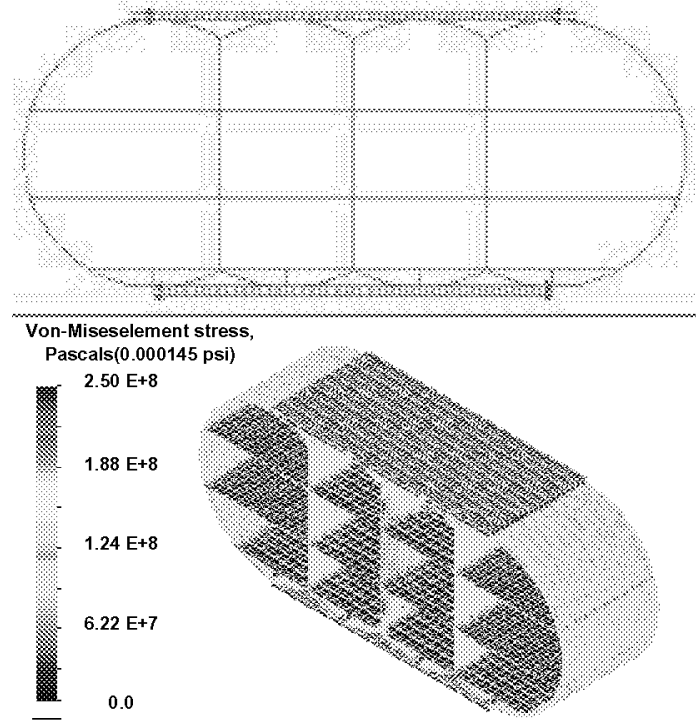

Fig. 8 Four-bubble fuselage concept: Element nodal Von-Mises stress at top due to 84835 pascals (12.3 psi) internal cabin pressure and 164350 $\mathrm{kg} / \mathrm{meter}(9200 \mathrm{lbs} / \mathrm{in})$ span-wise compressive load on top panel and equal tensile load at bottom panel.

Five-bubble double-wall fuselage:

The five-bubble configuration, shown in Fig. 9 was conceived and analyzed with internal design pressure loads, as well as with estimated equivalent compressive loads on top panels (and equal tensile load on bottom panels) due to fuselage bending, in order to obtain acceptable stress, deflection and buckling stability safety factor. Based on plate buckling analysis ${ }^{13,14}$ the top and bottom double wall depth was chosen as 0.15 meter with 0.003 meter thick span-wise running ribs at 0.25 meter interval. Radius of inner cabin vaulted ceiling were reduced from $3.875 \mathrm{~m}$ to 3.75 meters. Radius of the outer cabin was calculated to be 3.248 meters in order to get approximate membrane stress equilibrium at outboard joints. Additional spanwise running tie-rods were also used at the top and bottom of the cabin. Since only half the fuselage was modeled, symmetric clamped boundary conditions were assumed at the plane of symmetry. 


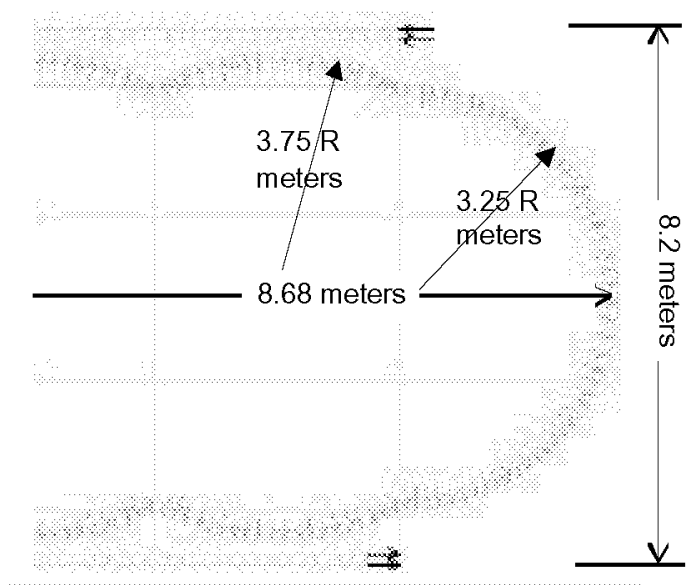

Fig. 9 Five-bubble fuselage with ribbed outer double-wall: Force-balanced stiffened fuselage concept

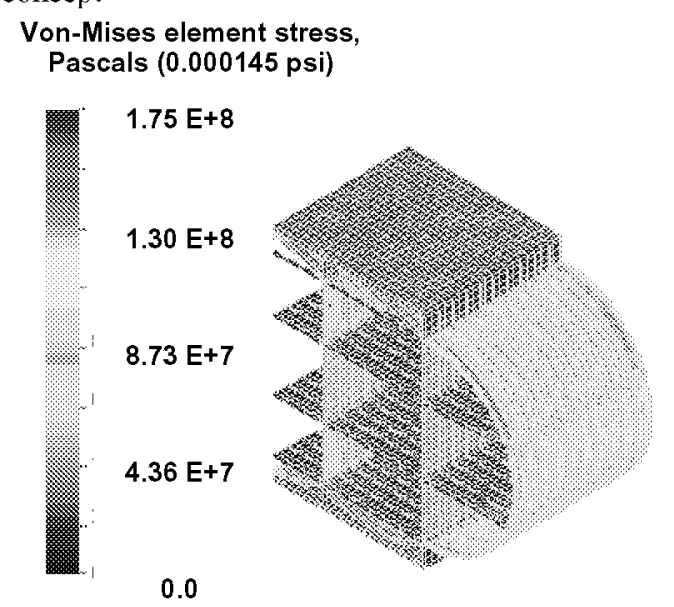

Fig. 10 Five-bubble fuselage with ribbed outerwall: Element nodal Von-Mises stress distribution at top surface due to 84835 pascals internal cabin pressure and $164350 \mathrm{~kg} / \mathrm{meter}$ span-wise compressive load on top panel and equal tensile load at bottom panel.

Initial results of the redesigned multi-bubble fuselage appear to be interesting. Maximum displacements were of the order 0.018 meters at the outer cabin walls and inside vaulted ceiling midspan. Figure 10 shows Von-mises stress distribution at element nodes computed on top surface due to combined internal cabin pressure and span-wise compressive load on top panel and equal tensile load at bottom panel. These stresses were well within allowable limits and about $25 \%$ lower than the four-bubble design with about $10 \%$ increase in unit weight/floor area. Buckling safety factor for pressure alone was -1.0 , indicating cylindrical shell buckling for a reversed pressure direction. With this cross-ribbed outer wall design, which was similar to those of the panel shown in Fig. $3 b$, buckling safety factors with the design compressive load were satisfactory. However, the fine mesh FEM model exhibited many lower local plate buckling modes, due to the manner in which the compressive forces were applied at nodes, to represent bending loads approximately. The vertical supports between outer double-wall and vertical cabin walls exhibited many lower local panel buckling modes with buckling safety factors starting from 0.7 to 1.95 for the first 20 modes. The total weight of this half FEM model was about $5176 \mathrm{~kg}$ with a floor area of $115 \mathrm{sq}$. meters.

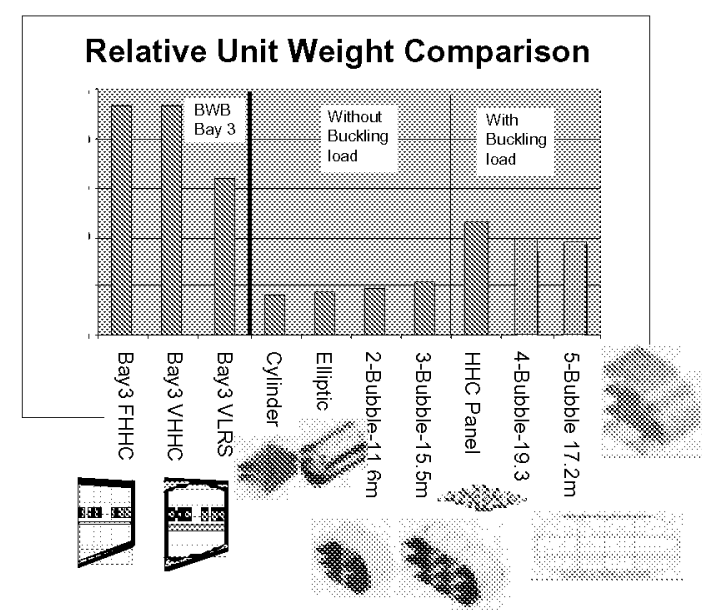

Fig.11 Relative FEM weight per unit floor area.

\section{Unit Weight comparison}

It would be difficult to make a fair comparison of different concepts that were analyzed due to the fact that each concept was a different model of a particular component of the fuselage with their own representative loading and boundary conditions, and did not include wing structure or other super structures. However, an initial attempt was made to estimate the fuselage component unit FEM weight per unit payload floor area and observe the trend. Summary of this comparison is shown in Fig. 11.

These relative unit weights were computed as ratio of total finite element weight of the structure divided by floor areas inside the fuselage section. First three concepts labeled BWB Bay -3 weights of vaulted shell with heavy honeycomb (VHHC); flat sandwich shell with heavy honeycomb core (FHHC); and vaulted ribbed shell (VLRS) also included side walls, front and rear pressurized spar of similar construction ${ }^{5}$. It should be noted that these previous designs were not optimized or analyzed for buckling stability, although sizing was done using 2-D nonlinear beam-column analysis similar to that described earlier in the paper. 
For all the cylindrical, elliptic and 2bubble and 3-bubble concepts, the total FEM weight was divided by floor area that included two passenger floor and one cargo floor, in order to obtain the unit weight ratio. Unlike previous BWB bay-3 analysis, weights did not include pressure bulkhead. For the case heavy honeycomb core rectangular (HHC) panel described earlier in Fig. $3 a$, FEM based weight was multiplied by 2 to account for bottom panel, floor, side walls or pressure bearing spar for an approximate equitable comparison. This modified weight was simply divided by panel area to get the unit weight ratio shown in the figure. These estimates appear consistent with that of $\mathrm{FHHC}$ case studied previously ${ }^{5}$. As a rule of thumb, FEM based weights are generally $40-50 \%$ lower than an actual fabricated structure. However, this unit weight comparison confirm two previously known hypothesis, and provide some quantitative values, namely: 1) The multi-bubble non-cylindrical pressure vessel configurations appear to be twice as inefficient compared to cylindrical structure, and, 2) Proper integration of partially cylindrical surfaces in pressurized fuselage design could reduce the overall weight by about $20-30 \%$ compared to using all flat surfaces.

\section{Conclusions}

A set of structural concepts for pressurized fuselage of blended-wing-body type flight vehicles were presented. A multi-bubble fuselage configuration concept was developed for balancing internal cabin pressure load efficiently, through balanced membrane stress in inner cylindrical segment shells and inter-cabin walls. In order to provide buckling stability and carry span-wise bending loads, additional cross-ribbed outer shell structure appear to be quite effective. Thus, it was advantageous to use the inner cylindrical shells for pressure containment and let the outer shells resist overall bending. This decoupling may enable both components to stay in a membrane state of stress, with minimal bending. The duct-space between inner- and outer-shell could be used for a direct ventilation system with potential weight and power savings. However, in case of a cabin pressure leak during flight, the outer ribbed shell was strong enough to withstand operational cabin pressure, thus providing adequate redundancy. Additional safeguard in this regard could be provided by venting the duct space through pressure valves. Nevertheless, further studies for refinement and optimization of these concepts are necessary, for gaining acceptance by the industry.

\section{Acknowledgement}

The authors wish to thank Dr. Dennis Bushnell for funding this project through his 'Creativity and Innovation' Initiative. Thanks are also due to Drs. Robert Liebeck and Sean Wakayama of Boeing Company and Dr. Gary Vanderplaats of VR\&D Inc. for their insight and critique.

\section{References}

${ }^{1}$ Liebeck, R. H. "Configuration Control Document CCD-3: Blended Wing Body:" Final report Under Contract NAS1-20275 NASA Langley Research Center, Oct. 1, 1997.

${ }^{2}$ Liebeck, R. H., Page, M. A., and Rawdon, B. K. "Blended-Wing-Body Subsonic Commercial Transport." AIAA Paper 98-0438, Jan. 1998.

${ }^{3}$ Dorsey, J., et. al., 'Airframe Integration Trade Studies for a Reusable Launch Vehicle,' Paper No. 247, Space Technology \& Application Forum, Albuquerque, NM, Jan. 31-Feb. 4, 1999.

${ }^{4}$ Hitch, H. P. Y., " Pressure Cabins Of Elliptic Cross Section," Aeronautical Journal, Vol. 92 No. 916 Jun-Jul. 1988, pp. 207-223.

${ }^{5}$ Mukhopadhyay, V., 'Structural Concepts Study of Non-circular Fuselage Configurations,' Paper No. AIAA SAE WAC-67, World Aviation Congress, Los Angeles, Calif. Oct. 22-24, 1996.

${ }^{6}$ Wakayama, S. and Kroo, I., "The Challenge and Promise of Blended-Wing-Body Optimization." AIAA Paper 98-4736, Sept. 1998.

${ }^{7}$ Smith, H., et al. "Blended Wing Body Airliner: Air Vehicle Design," Cranfield University, Web

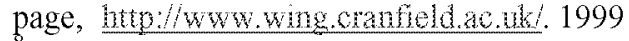

${ }^{8}$ Morrocco, J. D. and Flottau, J., "Europe Seeks Global Leadership in Aeronautics," Aviation Week and Space Technology, February 5, 2001, pp. 3031.

${ }^{9}$ Timoshenko, S. P. and Gere, J. M., "Theory of Elastic Stability," McGraw Hill Book Co., New York, 1961, pp. 1-11.

${ }^{10}$ GENESIS V6.0: Structural Analysis and Optimization, Vol. I Overview, Vol.2 Reference, Vanderplaats R\&D Inc. January 2000.

${ }^{11}$ COSMOS/M Basic FEA System User's Guide, Structural research and Analysis Corporation, Santa Monica, CA, 1993.

${ }^{12}$ Bruhn,E. F., "Analysis and Design of Flight vehicle Structures," Tri State Offset Co., 1965, pp.A16.1-A16.9 and pp.C11.29-C12.51

${ }^{13}$ Young, Y. C.,'Roark's Formulas for Stress and Strain, McGraw Hill Ed.6, 1989, pp.515-643

${ }^{14} \mathrm{Niu}, \mathrm{M} . \mathrm{C}$. Y., "Airframe Structural Design," Conmilit Press Ltd., Hong Kong, 1993, pp. 376428. 
Table 1. Summary of results from the 2-D beam column and 3-D panel finite element analysis and optimization.

\begin{tabular}{|l|l|l|l|l|ll|l|l|l|l|}
\hline Concept & Initial & & & & optimized & & & \\
\hline & depth & skin $\mathrm{t}$ & $\mathrm{P} / \mathrm{Pcr}$ & wt/area & depth & skin & $\mathrm{P} / \mathrm{Pcr}$ & wt/area max disp & material \\
& meters & meters & meters & $\mathrm{kg} / \mathrm{sq} . \mathrm{m}$ & meters & meters & meters & $\mathrm{kg} / \mathrm{sq} . \mathrm{m}$ & meters & \\
\hline 2D HC Beam & 0.150 & 0.006 & 0.40 & 42.44 & 0.2642 & 0.0045 & 0.18 & 37.9 & 0.0300 & $\mathrm{AL}$ \\
Flat HC & 0.137 & 0.003 & 0.50 & 15.3 & 0.2007 & 0.0046 & 0.66 & 24.1 & 0.0086 & comp \\
Flat ribbed & 0.152 & 0.003 & 0.50 & 13.5 & 0.1842 & 0.0058 & 0.66 & 25.6 & 0.0064 & comp \\
Flat HC+Cat & 0.167 & 0.003 & 0.50 & 15.4 & 0.2007 & 0.0046 & 0.71 & 24.2 & 0.0090 & comp \\
Vaulted HC & 0.200 & 0.003 & & 17 & 0.1702 & 0.0033 & 0.66 & 25.4 & 0.0112 & comp \\
\hline
\end{tabular}
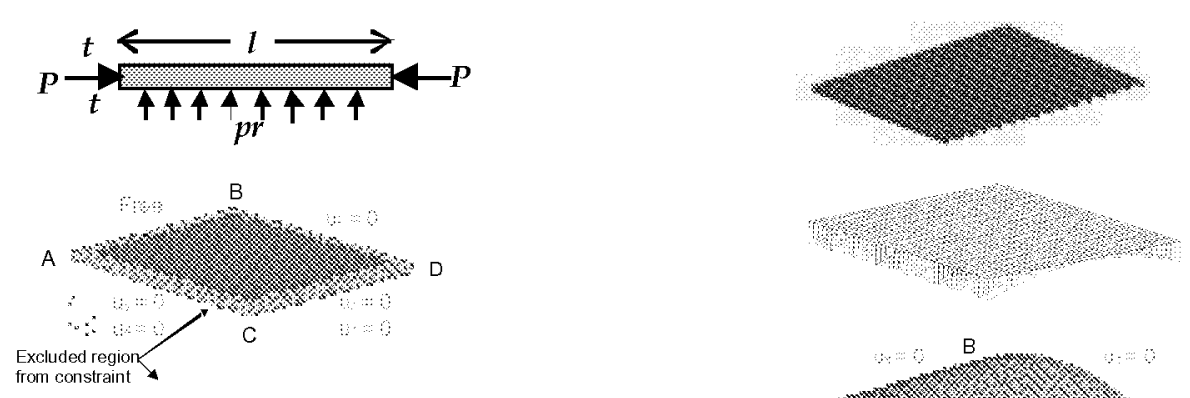

Excluded region
from constraint

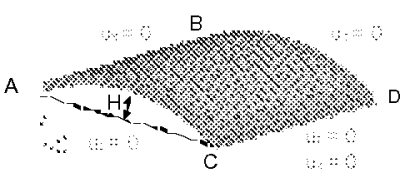

